\title{
Back pain and sacroiliitis in long-standing adult celiac disease: a cross-sectional and follow-up study
}

\author{
Cumali Efe $\cdot$ Tugrul Purnak $\cdot$ Ersan Ozaslan • \\ Zeynep Ozbalkan
}

Received: 2 October 2009 / Accepted: 7 February 2010 / Published online: 20 February 2010

(c) Springer-Verlag 2010

To the editor:

We read with great interest the study report of Vereckei et al. [1] regarding sacroiliac joints involvement in patients with celiac disease (CD). They evaluated 21 consecutive patients with proven $\mathrm{CD}$ for the study. Bone scintigraphy indicated in 5/21 (24\%) of them have sacroiliac involvement and radiography in 10/21 (47.6\%).

Arthricular involvement has been reported prevalently in CD. Moreover, arthritis may be the first clinical presentation before the gastrointestinal symptoms occur. Bourne et al. [2] reported six patients with CD in whom arthritis was prominent at diagnosis. Also they reported HLA-A1, B8, DR3 positivity in five and B27 positivity in two patients and they claimed that genetic susceptibility may be one of the most important pathogenetic mechanism of arthritis in these patients. It is known that HLA-B27 positivity has a crucial role in the pathogenesis of inflammatory bowel diseases associated sacroileitis. For this reason, we think that authors should mention the HLA status of their study group.

Secondly, in the study, approximately eight patients had reported moderate back pain in spite of gluten-free diet. On the other hand, five patients complained of continuous pain after 11 years of follow-up. We wonder that was there any therapy for these patients such as corticosteroid or non-steroidal anti-inflammatory drug, in addition to gluten-free diet during the 11-years follow-up?

\section{References}

1. Vereckei E, Mester A, Hodinka L, Temesvári P, Kiss E, Poór G (2009) Back pain and sacroiliitis in long-standing adult celiac disease: a cross-sectional and follow-up study. Rheumatol Int 30:455-460 PMID: 19504097

2. Bourne JT, Kumar PE, Huskisson CR, Mageed D, Unswort J, Wajtulewskı JA (1985) Arthritis and coeliac disease. Ann Rheum Dis 44:592-598

\section{Efe $(\square)$}

Internal Medicine Department, Ankara Numune Research

and Education Hospital, Yazgan sokak 21/12 Cebeci,

Ankara, Turkey

e-mail: drcumi21@hotmail.com

T. Purnak · E. Ozaslan

Gastroenterology Department,

Ankara Numune Research and Education Hospital,

Ankara, Turkey

\section{Z. Ozbalkan}

Rheumatology Department,

Ankara Numune Research and Education Hospital,

Ankara, Turkey 